\title{
Encontrando lo que nunca estuvo perdido. Conciencia de clase y conflicto de clases en el régimen neoliberal chileno
}

Pablo Pérez Ahumada ${ }^{1}$

\begin{abstract}
Resumen
En esta investigación se examinan las pautas generales del conflicto de clases en la sociedad chilena contemporánea. Para ello, se examina la manera en que las clases sociales poseen distintas orientaciones sociopolíticas sobre temáticas referentes al conflicto de clases. Más específicamente, esta investigación recurre a la literatura sobre conciencia de clase para analizar tres componentes centrales de la conciencia de clase de los individuos: 1) Identidad de clase, 2) Percepciones del conflicto de clase, 3) Actitudes hacia la intervención del Estado en la economía (en tanto este tema es un punto central de los regímenes neoliberales). A partir de una serie de modelos de regresión logística ordinal se examina qué componentes de la conciencia de clase se encuentran más polarizados. Así, se busca entender la manera en que el conflicto de clases expresado en la polarización de opiniones y actitudes se estructura en un régimen neoliberal que-como el chileno- está caracterizado por niveles importantes de despolitización, por la debilidad de actores colectivos de clase trabajadora (sindicatos) y por la ausencia prácticas de partidos que representen los intereses de la clase trabajadora. Los hallazgos muestran que a pesar de este escenario desfavorable, la clase continúa siendo un aspecto central en la configuración de orientaciones ideológicas antagónicas, lo cual puede ser la fuente de importantes conflictos políticos en el futuro.
\end{abstract}

Palabras clave: Conciencia de clase - conflicto de clases - neoliberalismo - Chile.

\begin{abstract}
In this research I examine the patterns of class conflict in contemporary Chilean society. To do so I focus on how the different social classes support dissimilar sociopolitical orientations towards several class-related issues. In particular, this research draws on the literature on class consciousness to analyze three main components of people's class consciousness: 1) Class identity, 2) Perceptions of class conflict, 3) Attitudes toward state intervention in the economy (as this issue is a central point of neoliberal regimes). On the basis of several ordinal logistic regression models, I examine which of these components of class consciousness are more polarized. By doing so I aim to understand how class conflict expressed in the polarization of opinions and attitudes is structured in a developed neoliberal regime which -as the Chilean-is characterized by high levels of depoliticization, weak working class actors (e.g. unions, ) and the practical absence of labor parties. The findings show that despite such an unfavorable scenario, social class is still a salient foundation for antagonistic ideological orientations. This may probably be the source of important political conflicts in the future.
\end{abstract}

Keywords: Class consciousness - class conflict - neoliberalism - Chile.

1 University of California, San Diego. Correo electrónico: paperez@ucsd.edu 


\section{ESTRUCTURA DE CLASES Y CONCIENCIA DE CLASE EN LAS SOCIEDADES NEOLIBERALES: EL CASO DE CHILE}

A diferencia de otros países latinoamericanos, la dictadura chilena reemplazó el antiguo modelo de sustitución de importaciones con un régimen económico altamente liberalizado. Junto con ello, los cambios asociados al entonces emergente régimen neoliberal chileno (precarización del mercado del trabajo, deterioro de los sindicatos, etc.) fueron impuestos sin la presencia de una clase trabajadora organizada, la cual fue políticamente reprimida durante la dictadura militar (Drake, 1996). Por ello el impacto de dicha transformación económica fue más profundo que en el resto de la región. Más aún, la llegada de los gobiernos democráticos en 1990 no implicó -como ha sido ampliamente señalado- un cambio sustantivo en dichas políticas desarrolladas desde finales de los años 70. En efecto, los marcos generales instaurados por la dictadura, así como muchos de sus anclajes institucionales (por ejemplo, la constitución política y el sistema electoral binominal) no han sido tocados en más de 20 años de gobiernos civiles. Al mismo tiempo, desde inicios de los 90 los principales actores colectivos de clase que operaron durante gran parte del siglo XX, como el movimiento sindical e incluso organizaciones profesionales de clase media como el colegio de profesores y las asociaciones del empleados públicos, han sido incapaces de recuperar la influencia política que tuvieron hasta 1973. Así, a pesar de las nuevas condiciones democráticas, en los años 90 y la primera década del 2000 no pareció haber mayores organizaciones colectivas clase, tal como el antiguo movimiento sindical, capaces de revertir efectivamente el marco general de políticas neoliberales y las condiciones desfavorables para los trabajadores emergidas de estas (Drake, 2003).

Esto ha producido una situación bastante paradójica en la sociedad chilena contemporánea. En efecto, a pesar de la estabilidad institucional y las altas tasas de crecimiento económico observadas durante los últimos 25 años, Chile presenta uno de los niveles de desigualdad más altos de la región. De modo similar, la situación de la mayoría de los trabajadores es extremadamente precaria (y se podría decir, casi tan precaria como en la dictadura), en virtud de que el principal marco regulatorio de las relaciones laborales instaurado por la dictadura -el Plan Laboral de 1979- no ha sido modificado hasta nuestros días. Como resultado de ello, los trabajadores chilenos no solo se ven afectados por bajos salarios y altos niveles de flexibilidad laboral, sino que también no poseen un real poder negociador ante los empleadores debido a que los sindicatos, una herramienta prototípica de presión del trabajo ante el capital, están extremadamente limitados por la ley (Barret, 2001; Frank, 2004; López, 2009; Leiva, 2012).

En este contexto de neoliberalismo hegemónico, diversas investigaciones analizaron la manera en que las políticas de liberalización económica transformaron la estructura de clases chilena (Martínez y Tironi, 1985; León y Martínez, 2007; Wormald y Torche, 2004). En general, todas estas investigaciones desarrolladas entre finales de los 80 e inicios de la década del 2000 mostraron que el declive del modelo substitutivo de importaciones y la estabilización del régimen neoliberal en Chile fue acompañado de la contracción del sector manufacturero-industrial y del crecimiento de la fuerza de trabajo empleada en el sector 
privado de servicios. En efecto, tanto en Chile como América Latina el sector de servicios y, en algunos casos, el sector informal, llegaron a ser las principales fuentes de empleo para una parte importante de la antigua clase trabadora industrial (CEPAL, 2006; Klein y Tokman, 2000; León y Martínez, 2007; Weller, 2004). Así, aun cuando las tasas de empleo informal en Chile han permanecido menores que en el resto de la región, las pautas generales de desindustrialización de la economía son básicamente las mismas. Por ejemplo, según datos del Ministerio del Trabajo, en 2008 el 33\% de la fuerza de trabajo chilena se encontraba empleada en el sector industrial, mientras que el $57 \%$ lo hacía en actividades de servicios.

Estos cambios han sido una de las principales barreras estructurales detrás del debilitamiento de las identidades tradicionales de clase trabajadora y de clase media, así como de la incapacidad que ambas clases han tenido para entablar mecanismos de acción colectiva en defensa de sus intereses (Angelcos et al., 2006; Barozet y Fierro, 2011; Drake, 2006; León y Martínez, 2007). En contraposición con la situación de la clase trabajadora y la clase media, las transformaciones neoliberales dieron origen a una poderosa clase empresarial cuya cohesión ideológica interna y su capacidad de influencia política ha podido ser vista en aspectos como su férrea defensa del Plan Laboral de 1979 y sus sólidos lazos con los partidos políticos de derecha e incluso con la Concertación, los cuales han definido los cauces de la transición democrática desde inicios de los años 90 (Barret, 2001; Frank, 2004; Silva, 1996).

En este paradójico escenario, diversos investigadores han analizado la manera en que la clase trabajadora y la clase media han tratado de regenerar su identidad colectiva después de la consolidación del régimen neoliberal. En relación con la clase trabajadora, las investigaciones han demostrado que una parte de los trabajadores chilenos ha recuperado sus espacios generadores de identidad -destruidos tanto por los cambios económicos como por la represión dentro y fuera de sus espacios de trabajo- fundamentalmente a través de microprácticas de resistencia ante las arbitrariedades de los empleadores (cf. Baltera y Dussert, 2010; Leiva, 2009; Leiva, 2012; Klubock 2004; Winn, 2004). Tal tipo de prácticas pueden ser observadas, según señalan estas investigaciones, en diversos tipos de organizaciones sindicales utilizadas para combatir las expresiones más concretas del proyecto neoliberal, como la precariedad en el empleo, la flexibilidad laboral y las prácticas antisindicales. En relación con la clase media, recientes investigaciones han apuntado cómo los miembros de dicha clase han tendido, en un contexto de alta heterogeneidad ocupacional, a construir una nueva identidad definida fundamentalmente en términos simbólicos (Méndez y Gayo, 2007; Méndez, 2008, 2010). Aun cuando este tipo de identidad de clase media no es necesariamente articulada en términos colectivos, ella sí es usada para generar barreras simbólicas y morales; específicamente, una barrera basada en un fuerte "sentido de autenticidad" (Méndez, 2008).

Como se puede ver, todas estas investigaciones dan cuenta de la manera en que las clases sociales articulan su identidad colectiva en un contexto marcado por las rápidas y profundas transformaciones acaecidas durante los últimos 30 años. Sorprendentemente, el concepto de conciencia de clase ha estado ausente de todos estos análisis. Así, por ejemplo, el estudio de la manera en que este escenario sociopolítico afecta la conciencia política de los trabajadores se ha enfocado solamente en sus percepciones y actitudes 
hacia los conflictos laborales, sin examinar cómo ellos se perciben a sí mismos como miembros de un colectivo más amplio, a saber, la clase trabajadora. En términos generales, no existen análisis recientes sobre la manera en que sujetos de distintas clases definen su situación particular de clase como el resultado de relaciones sociales más generales y amplias -por ejemplo, como el resultado de la desigualdad de poder entre clases o la desigual distribución de recursos entre ellas-. Tampoco existen investigaciones recientes que den cuenta de la forma en que sujetos de distintas clases perciben el conflicto de clases o los intereses políticos relacionados con dinámicas de clase (por ejemplo, la manera en que los empresarios y capitalistas definen como "legítimo" o "ilegítimo" las demandas a favor de la redistribución del ingreso o la forma en que la clase trabajadora y la clase media apoyan la intervención del Estado en la economía en contraposición a los principios de mercado dominantes hoy en día). Como consecuencia de esto, la pregunta por los mecanismos a través de los cuales la desigualdad de clase conduce a percepciones desiguales e incluso conflictivas del régimen neoliberal ha sido apenas planteada. Así, los debates académicos recientes han tendido a pasar por alto la pregunta por el conflicto de clases en Chile, aun cuando la aceptación pasiva de los principios neoliberales ha sido fuertemente puesta en duda en los últimos años como consecuencia de diversos tipos de movilización social (movilizaciones estudiantiles, huelgas de trabajadores contratistas, demanda generalizada por la extensión de derechos sociales, etc.) basados en una agenda explícitamente antineoliberal.

Tomando como base este diagnóstico, el objetivo central de esta investigación es caracterizar las pautas centrales del conflicto de clases en Chile a partir del análisis de la manera en como las distintas clases sociales apoyan diferentes orientaciones sociopolíticas en relación con una serie de fenómenos relacionados con el conflicto de clases. Más específicamente, esta investigación se basa en la literatura sobre conciencia de clase a fin de examinar cómo la clase social determina diferencias tanto en la identidad como en los intereses de clase.

\section{APROXIMACIONES AL CONCEPTO DE CONCIENCIA DE CLASE}

Desde los análisis de Marx hasta nuestros días, la conciencia de clase ha sido estudiada analizando el proceso por medio del cual una clase llega a ser consciente de sus intereses, actuando de ese modo en la arena política en contra de los intereses de otras clases (cf. Marx, 1978 [1852]; Lukács, 1971 [1923]). El concepto de conciencia de clase también ha sido definido en términos más concretos a través de argumentos basados principalmente en sus atributos culturales. A modo de ejemplo, el historiador inglés E. P. Thompson señala que la conciencia de clase trabajadora debe ser entendida como la definición "cultural" que los trabajadores hacen de sus experiencias económico-productivas: "La conciencia de clase es la forma en que esas experiencias se expresan en términos culturales: encarnadas en tradiciones, sistemas de valores y formas institucionales" (1966: 10).

El marco analítico de Thompson enfatiza diversas características de la conciencia de clase que nos permiten explicar el proceso de formación de clases -es decir, el proceso a través del cual las clases se convierten en actores colectivos conscientes de sus intereses-. 
La principal virtud de este marco de análisis es que permite entender la formación de clases no como la consecuencia mecánica de algún tipo de estructura de clases "objetiva", sino que más bien como el proceso cultural por medio del cual los miembros de una clase (los trabajadores, por ejemplo) llegan a ser conscientes de su situación de clase. Sin embargo, se ha señalado que este esquema depende mucho del énfasis teleológico de Thompson, a partir del cual se asume que una vez que ciertas condiciones externas "producen" a la clase trabajadora, ella comienza a hacer de sí misma una fuerza revolucionaria. Según Katznelson (1986: 21), el problema con esta visión teleológica radica en que la formación de clase es entendida sólo como el punto de partida de un resultado definido a priori -a saber, una clase trabajadora revolucionaria- sin considerar otros posibles resultados como una clase trabajadora no revolucionaria (una reformista, por ejemplo).

Más allá de este tipo de críticas, el análisis de Thompson ha sido ampliamente usado en los debates sociológicos sobre conciencia de clase. Fantasia (1988), por ejemplo, enfatiza tanto la noción marxista de praxis en tanto actividad humana consciente como la definición que Thompson hace de la conciencia de clase para argumentar que la conciencia de clase denota un amplio rango de prácticas culturales generadas por los trabajadores en sus luchas sociales (por ejemplo, en el desarrollo de huelgas y en su participación en conflictos con los empleadores). Según Fantasia, todos esos "momentos de crisis" acaecidos a nivel local en las fábricas, en los lugares de trabajo o al nivel comunitario, representan de manera fidedigna la emergencia de lo que él define como culturas de solidaridad. Al igual que Fantasia, Brenner argumenta que la manera más productiva de entender los mecanismos de solidaridad entre los miembros de una clase es a través de sus "experiencias cotidianas de conflicto y cooperación en los lugares de trabajo" (1989: 185). Ella argumenta, tal como lo hace Thompson, que un análisis de aquellas experiencias vividas de los trabajadores pueden capturar los mecanismos que conectan su conciencia con los Ilamados "intereses objetivos", definidos en términos de las relaciones de explotación en las cuales ellos están inmersos. Tal tipo de conexión es la que no se encuentra explicada, según ella, por los análisis "estructuralistas" de la conciencia de clases, como el planteado por Erik O. Wright $(1985,1997)$.

Este tipo de aproximación "estructuralista" a la conciencia de clase ha sido, de hecho, una de las perspectivas más influyentes en los debates sociológicos de las últimas décadas (Crompton, 1993: 58). El punto de partida de este tipo de análisis se encuentra en la afirmación de la existencia de una estructura de clases objetiva basada en relaciones de explotación. El principio básico es que la conciencia de clase se refiere al reconocimiento que los sujetos hacen de sus intereses de clase definidos objetivamente por la posición que ellos ocupan en las relaciones de explotación (es decir, por su posición de clase). Dicho de otra manera, esta perspectiva no está preocupada en definir la conciencia de clase a partir de la emergencia de una identidad cultural entre los miembros de una clase, sino que más bien en términos de cómo los miembros de distintas clases reconocen sus intereses materiales (Wright, 1997: 495). Al mismo tiempo, la conciencia de clase, como es definida por Wright, es tratada como un concepto de nivel micro, es decir, como un atributo de los individuos miembros de una clase antes que de las colectividades -las clases no tienen "conciencia" en el sentido literal del término-. 
Esta definición "individualista" de la conciencia de clase es, sin embargo, cuestionable, ya que no establece claramente cómo y bajo qué condiciones un individuo consciente de sus intereses de clase actuará en defensa de ellos (Marshall et al., 1988: 191-194). En este sentido es que Offe y Wiesental (1980) han argumentado que cualquier definición de la conciencia de clase debe tomar en cuenta el proceso colectivo por medio del cual las clases definen sus intereses y actúan en la defensa de ellos. Según Offe y Wiesental, esto es especialmente relevante al estudiar la conciencia de clase trabajadora, ya que el elemento central de ella -la definición de intereses y visiones de mundo comunes- está basado en relaciones dialógicas en donde el elemento colectivo asociado al diálogo es la piedra fundamental; esto a diferencia de lo que ocurre en la clase capitalista en donde la definición de intereses comunes se basa fundamentalmente en relaciones instrumentales.

Cada una de las conceptualizaciones recién revisadas puede ser agrupada, a partir de la manera en como definen la conciencia de clase, en dos grandes perspectivas de investigación: la procesual y la estructural (Wallace y Junisbai, 2004; Wright, 1997). En la primera de ellas (cf. Thompson, 1966), la conciencia de clase es empíricamente analizada a partir de las experiencias históricas de clase que configuran la identidad de clase de los individuos. En la segunda (Wright, 1985), la conciencia de clase es estudiada a partir de la manera en que la posición de clase actual de los individuos configura sus intereses de clase. Así, en términos de la investigación empírica, ambas perspectivas enfatizan distintas dimensiones de la conciencia de clase. Mientras que investigaciones cercanas a la perspectiva procesual han tendido a definir la conciencia de clase en términos de la autoidentificación que las personas hacen de su situación de clase (ver, por ejemplo, Lockwood, 1989 [1958]; Vanneman y Weber Cannon, 1987), aquellos estudios ligados al enfoque estructural han tratado la conciencia de clase fundamentalmente en términos de cómo los individuos de distintas clases sostienen diferentes intereses sociopolíticos en tanto expresión de sus intereses de clase (cf. Western, 1999; Wright, 1997). En estas investigaciones, en efecto, la identificación de clase no es usada como un indicador de la conciencia de clase, sino que más bien como una variable independiente que configura la conciencia de los intereses de clase (Wallace y Junisbai, 2004: 388). Algunos analistas, sin embargo, han argumentado en favor de un enfoque integrado en donde la identidad y los intereses de clase sean incluidos en la misma definición de la conciencia de clase. Según esta perspectiva integrada, el análisis de la conciencia de clase se debe basar tanto en el estudio de los intereses de clase de los individuos determinados por su posición de clase como en su identidad de clase, en tanto derivada de sus experiencias vividas de clase. En términos de la investigación empírica esto implica que la pregunta por la autoidentificación de clase deba ser tratada como variable dependiente -o sea, como un componente de la conciencia de clase- antes que como una variable independiente que actúe sobre el reconocimiento que las personas hacen de sus intereses de clase (ver, por ejemplo, Ayalon et al. 1987; Buttel y Flinn, 1979; Marshall et al., 1988; Vallas, 1987; Zingraff y Schulman, 1984).

Además de la distinción entre las perspectivas estructural y procesual, un elemento importante en el estudio de la conciencia de clase proviene de la distinción analítica de "etapas" o "niveles" dentro de ella. Tal distinción ha sido usada durante las últimas décadas 
para explicar la ausencia práctica de una conciencia revolucionaria en la clase trabajadora de las naciones industrializadas. Diversos análisis (cf. Buttel y Flinn, 1979; Hazelrigg, 1973; Giddens, 1973; Mann, 1973) han argumentado que la conciencia de clase sigue siendo un elemento central para entender el conflicto social en el capitalismo, aun cuando ella se presente en variados niveles de desarrollo entre los cuales la conciencia "revolucionaria" es el más elevado (y el más improbable de alcanzar). Mann (1973), por ejemplo, señala que en las sociedades capitalistas contemporáneas la conciencia de clase trabajadora tiene que ser estudiada a partir de la distinción de cuatro elementos implicados en ella. Estos elementos son: 1) identidad de clase, es decir, la definición que los sujetos hacen de sí mismos como miembros de una clase que ocupan, junto a otros miembros de esa clase, un rol distintivo en las relaciones productivas; 2) oposición de clase, o sea, la percepción que los miembros de la clase trabajadora tienen del capitalismo y sus agentes en tanto oponentes a sus intereses de clase; 3) totalidad de clase, es decir, el reconocimiento de que los dos elementos definidos previamente definen tanto la situación de uno mismo en la sociedad como la situación de la sociedad en general; y 4) la concepción de una sociedad alternativa que se puede conseguir a partir de la lucha contra los oponentes de clase. Para Mann, una conciencia de clase verdaderamente revolucionaria -en el sentido marxista del términopuede ser vista solo en la combinación de estos cuatro elementos. De modo similar, y sobre la base de argumentos ligeramente diferentes, tanto Giddens (1973) como Hazelrigg (1973) señalan que en las sociedades capitalistas avanzadas existen varios niveles en la conciencia de clase trabajadora, entre los cuales el estado "revolucionario" denota el más avanzado y el más difícil de conseguir. En términos generales, la diferenciación de estos estados o niveles de la conciencia de clase permite aceptar la posibilidad de analizar empíricamente la conciencia de clase sin depender necesariamente de la existencia empírica de una conciencia revolucionaria. En otras palabras, tal diferenciación permite analizar la conciencia de clase en sus niveles primarios de desarrollo o en contextos en donde el conflicto entre clases no es necesariamente explícito.

Los debates recién detallados demuestran que una manera apropiada de estudiar la conciencia de clase es a través de la integración de las perspectivas procesuales y estructurales. Tal tipo de análisis integrado permite definir la conciencia de clase como un tipo específico de resultado, a saber, aquel atributo de las clases resultante del proceso por medio del cual ellas -así como los individuos que las conforman- construyen su identidad común y toman conciencia de sus intereses colectivamente creados. La naturaleza de tales intereses es también relevante para delinear la idea de conciencia de clase. En efecto, en la medida en que las clases se fundan sobre las relaciones capitalistas de producción (específicamente, sobre las relaciones de explotación y dominación imbricadas en ellas), los intereses de clase denotan siempre un conflicto sobre tal tipo de desigualdad material. Así, la conciencia de clase puede ser definida como el resultado del proceso a través del cual las clases construyen su identidad colectiva y llegan a ser conscientes de sus intereses de clase. Tanto los intereses como la identidad son una creación colectiva de los individuos que se encuentra, sin embargo, estructuralmente constreñida por las relaciones de producción que determinan los límites mismos de la existencia de las clases. En otras palabras, y siguiendo la terminología sociológica, en este trabajo se define la conciencia de clase como el resultado 
del proceso más general de formación de clases. Este resultado se expresa en la existencia de identidades e intereses de clase desiguales y antagónicos, derivados tanto de la posición actual de los individuos en las relaciones de producción (como sostiene la perspectiva estructural) como de sus experiencias vividas de clase (por ejemplo, sus orígenes de clase, tal como señala el enfoque procesual).

Una definición como esta implica considerar la posición de clase de los individuos y sus experiencias vividas de clase como las variables fundamentales para entender los mecanismos a través de los cuales la desigualdad de clase define variaciones en la consciencia sociopolítica y, eventualmente, diferentes posiciones políticas en un contexto concreto. Un marco de análisis integrado como este se presenta especialmente pertinente para entender las relaciones de conflicto entre las clases en las sociedades que, como la chilena, están definidas por un régimen neoliberal maduro caracterizado por altos niveles de desigualdad social. Como se señaló anteriormente, el objetivo central de esta investigación es caracterizar las pautas centrales del conflicto de clases en Chile a partir del análisis de la manera en la que la clase social (entendida en términos de la posición de los individuos en la estructura de clases y sus orígenes de clase) determina diferentes orientaciones sociopolíticas asociadas a la desigualdad de clase. Más específicamente, a partir de la distinción entre los distintos "niveles" de la conciencia de clase ya descrita, así como investigaciones empíricas sobre conciencia de clase en las sociedades capitalistas contemporáneas (Buttel y Flinn, 1979; Giddens, 1973; Hazelrigg, 1973; Jones, 2001; Mann, 1973; Vallas, 1987; Western, 1999; Wright, 1985), esta investigación se enfoca en tres componentes centrales de la conciencia de clase: 1) Identidad de clase, 2) Conciencia del conflicto de clase, 3) Actitudes hacia la intervención del Estado en la economía (en tanto este tema es un punto central del régimen económico neoliberal.) Mientras los dos primeros componentes representan los niveles más elementales de la conciencia de clase (conciencia de la propia situación de clase y del conflicto entre clases), el tercer componente representa, en términos generales, un nivel más elevado de ella (particularmente, una conciencia de los intereses de clase).

\section{DATOS, MÉTODOS E HIPÓTESIS}

Esta investigación está basada en datos provenientes de dos encuestas representativas de la población nacional (mayores de 18 años) aplicadas en 2008 (Encuesta de Trabajo y Equidad, $n=2.076$ ) y 2010 (Encuesta del Centro de Investigación en Estructura Social, CIES, $\mathrm{n}=794)$. En ambos casos se utilizó una submuestra representativa del total de población empleada en el país (casos empleados en las FF.AA fueron excluidos del análisis).

La relación entre la clase social y la conciencia de clase fue analizada a partir de diversos modelos de regresión logística ordinal. La regresión logística ordinal es una extensión de la regresión logística que se usa cuando la variable dependiente ("conciencia de clase" en este caso) es de tipo ordinal. Al igual que la regresión logística, este tipo de regresión funciona a partir de la transformación logarítmica de los coeficientes definidos como odds, que representan la probabilidad de éxito versus la probabilidad de fracaso de cualquier evento. Dicha transformación logarítmica produce coeficientes definidos como log-odds, los cuales 
permiten analizar la variable dependiente como si fuese una función lineal de las variables independientes a partir de coeficientes con límites infinitos $(-\infty,+\infty)$ (Powers y Xie, 2008: 6). Uno de los supuestos más importantes de este tipo de regresión es el supuesto de los odds proporcionales. Según este, la relación entre cada par de categorías de las variables dependiente e independientes es la misma. Así, por ejemplo, se asume que el coeficiente que describe la relación entre la categoría menor versus las categorías más altas de la variable dependiente (por ejemplo, tener baja conciencia de clase versus tener un nivel medio y alto de conciencia de clase) es el mismo que el que permite describir la relación entre las siguientes categoría versus las más altas categorías de la variable dependiente (nivel bajo/ medio de conciencia de clase versus nivel alto), y así sucesivamente. En términos prácticos este supuesto significa que, en la medida en que la relación entre los pares de categorías es la misma, solo es necesario un conjunto de coeficientes -es decir, un modelo- para describir la relación global entre las variables dependiente e independientes.

Un análisis cuantitativo de la conciencia de clase como este no está exento de problemas. Muchos investigadores han criticado este tipo de estudios en virtud de su aproximación descontextualizada a los procesos a través de los cuales los miembros de una clase construyen en la práctica su conciencia de clase (Fantasia, 1988; Marshall, 1883). De acuerdo con este tipo de críticas, la mejor manera de estudiar la conciencia de clase es a través del análisis de las luchas y acciones por medio de las cuales las influencias de la clase social son prácticamente realizadas. Si bien estas críticas son razonables, esta investigación sigue a aquellos que argumentan que la conciencia de clase, así como otros efectos de la clase social como las actitudes y percepciones, pueden ser adecuadamente analizados a través de técnicas cuantitativas (ver, entre otros, Jones, 2001; Svallfors, 2006; Western, 1999; Wallace y Junisbai, 2004; Wright, 1985, 1997). Aunque limitadas, las técnicas cuantitativas pueden ser útiles para entender las pautas generales del conflicto de clase expresadas, a nivel macro, en la polarización de las orientaciones ideológicas de clase, opiniones y actitudes. Las técnicas cuantitativas pueden no ser útiles, por cierto, para dar cuenta de la manera en que las personas articulan su conciencia de clase o para explicar bajo qué condiciones un tipo específico de conciencia de clase (por ejemplo, una conciencia reformista) se desarrolla a expensas de otras (una conciencia revolucionaria, por ejemplo). Sin embargo, la metodología cuantitativa sí es útil para explicar -tal como pretendo hacerlo en esta investigación- qué elementos de la conciencia de clase están más polarizados que otros y son, por tanto, más importantes para explicar el conflicto de clases en una sociedad determinada. Por eso, tanto las metodologías cuantitativas como cualitativas parecen ser buenos complementos para un examen empírico del conflicto de clases.

\subsection{Variables dependientes}

En este estudio la conciencia de clase fue medida a partir de tres variables. Cada una de ellas representa uno de los componentes de la conciencia de clase ya descritos. El primer componente, la identidad de clase, fue medido a partir de la variable definida como "Identidad de clase subordinada". Esta es una variable ordinal (1. Sin identidad de clase subordinada, 2. Identidad de clase subordinada moderada y 3 . Identidad de clase subordinada fuerte) que 
fue calculada sobre la base del "Índice de identidad de clase subordinada" (Ver apéndice 1 para detalles de todos los índices creados).

La segunda dimensión de la conciencia de clase, conciencia del conflicto de clases, fue medida a partir de la variable "Percepciones del conflicto entre los trabajadores y la administración (ejecutivos) de la empresa en la que trabaja el encuestado". Esta es una variable ordinal (1. Percepción baja, 2. Percepción moderada y 3. Percepción fuerte del conflicto entre trabajadores y ejecutivos) basada en el "Índice de percepción de conflictos laborales".

Por último, la tercera dimensión de la conciencia de clase -actitudes hacia la intervención del Estado en la economía- fue medida a través de la variable "Estatismo económico", la cual representa el grado de acuerdo con el enunciado "El Estado chileno debería ser el propietario de las principales empresas e industrias". Al igual que en los casos anteriores, esta es una variable ordinal de tres categorías (1. Bajo, 2. Moderado y 3. Fuerte apoyo a la intervención del Estado en la economía). El supuesto principal tras esta variable es que en vistas de que el proyecto neoliberal se basó en un profundo proceso de privatizaciones, el apoyo a políticas proestatistas debería ser visto, al menos en términos de política económica, como expresión de un programa antineoliberal. Este supuesto parece ser razonable considerando que gran parte del proyecto neoliberal se ha sustentado ideológicamente en la creencia de que la iniciativa privada es el mecanismo más eficiente para crear riqueza y de que el mercado es, a su vez, el medio más efectivo para distribuir recursos (Lechner, 1992).

En los tres casos las variables fueron codificadas de modo tal que a mayor el valor de ellas, mayor la conciencia de "clase trabajadora" (es decir, mayor identidad de clase subordinada, mayor percepción de los conflictos de clase y mayores actitudes proestatistas). Esta conciencia de clase trabajadora representa, en el fondo, una conciencia "antineoliberal". En efecto, ya que la clase trabajadora ha sido una de las clases más desfavorecidas por el proyecto neoliberal (cf. Winn, 2004), es esperable hipotéticamente que su conciencia sociopolítica represente, en términos generales, una postura crítica en contra de este tipo de régimen.

\subsection{Variables independientes}

\subsubsection{Clase social}

La variable independiente central de esta investigación es la clase social. Tal como se señaló anteriormente, la mejor manera de analizar la relación entre clase y conciencia de clase es a través de un análisis integrado de las perspectivas procesual y estructural. Por ello, en este trabajo los fenómenos ligados a la clase social serán entendidos tanto en términos de la posición de clase de los individuos (es decir, la clase en la que ellos se encuentran actualmente) como en términos de su origen de clase (en tanto indicador de las experiencias pasadas de clase).

La operacionalización del concepto de clase social está basada en el modelo de Erikson y Goldthorpe (1992). Dicho modelo fue empíricamente construido a partir de los algoritmos desarrollados por Ganzeboom y Treiman (2003). Tales algoritmos fueron 
especialmente útiles para construir tal esquema de clases sobre la base de preguntas convencionales presentes en las dos encuestas usadas en esta investigación (códigos de la CIUO, estatus de supervisor/no supervisor del encuestado y su condición de propietario/ no propietario de medios de producción). En principio, y en virtud de los objetivos de esta investigación, hubiera sido más adecuado utilizar el modelo de la estructura de clases desarrollado por E. O. Wright (1985). El modelo de Wright se presenta mucho más pertinente y teóricamente fundamentado para analizar no solo la posición de clase de los individuos, sino que también sus intereses materiales derivados de tal posición de clase. Sin embargo, la carencia de variables necesarias para su construcción -en especial las relacionadas con la operacionalización de los "bienes de organización"- hizo imposible tal tarea. Si bien el modelo Erikson y Goldthorpe no tiene estos problemas asociados a su construcción, sí presenta algunas limitaciones teóricas como la integración de altos ejecutivos y grandes empresarios en una misma categoría definida como "clase de servicio alta" (Ganzeboom y Treiman, 2003). Sin embargo, su aplicabilidad empírica y la confiabilidad de sus resultados derivados de su uso en investigaciones comparativas han hecho de este esquema casi un estándar en la investigación sociológica sobre las clases. En efecto, este esquema ha sido ampliamente usado en el estudio de la conciencia de clases, la movilidad social, el comportamiento político, y otras actitudes derivadas de las diferencias de clase (cf. Andersen y Heath, 2002; Evans, 1997; Hout et al., 1995; Marshall et al., 1988; Svallfors, 2006; Wormald y Torche, 2004). Además, se ha demostrado que la estructura de clases chilena puede ser representada fielmente a partir de los principios básicos de este modelo (Torche, 2006).

En esta investigación se usó una versión ligeramente modificada del esquema de Erikson y Goldthorpe. En vez de usar la versión de once categorías, los datos disponibles solo permitieron que la posición de clase de los encuestados fuera medida a través de una versión colapsada de ocho categorías: 1 . Clase de servicio alta (capitalistas más gerentes de alto nivel), 2. Clase de servicio baja (gerentes de nivel intermedio), 3. Empleados no manuales de rutina de nivel alto, 4. Empleados no manuales de rutina de nivel bajo, 5. Pequeña burguesía (autoempleados más pequeños empleadores), 6 . Trabajadores manuales calificados, 7. Trabajadores manuales no calificados, 8. Trabajadores agrícolas. De modo similar, los datos disponibles permitieron operacionalizar el origen de clase solamente a través de una versión colapsada de cinco categorías de clase derivada de la clase social de los padres de los encuestados. Las cinco categorías son: 1. Clase de servicio alta, 2. Clase media (incluye gerentes de nivel intermedio, empleados de rutina altos y bajos más aquellos definidos como parte de la pequeña burguesía), 3. Trabajadores manuales calificados, 4. Trabajadores manuales no calificados, 5. Trabajadores agrícolas.

La hipótesis central para la variables posición de clase y origen de clase es que aquellas personas definidas ampliamente como de la clase trabajadora o con origen de clase trabajadora tendrán más posibilidades de sostener una conciencia de clase trabajadora (es decir, una identidad de clase subordinada, una percepción alta de los conflictos de clase y un interés de clase proestatista) en relación con aquellos de la clase de servicio o con origen en la clase de servicio. 


\subsubsection{Variables demográficas}

Además de la clase social, los modelos de regresión incluyeron diversas variables demográficas: género, edad, estatus de jefe de hogar, lugar de residencia y nivel educacional. El género fue incluido como una variable dummy (categoría de referencia: mujer). La edad fue operacionalizada como variable de intervalo (edad del entrevistado en años). El estatus de jefe de hogar fue definido como una variable dummy (categoría de referencia: no es jefe de hogar). El lugar de residencia fue incluido también como variable dummy $(1=\mathrm{el}$ entrevistado vive en la Región Metropolitana de Santiago [RM], $0=$ el entrevistado no vive en la RM). Por último, el nivel educacional fue medido a partir de un set de variables dicotómicas (educación básica o menos, educación secundaria completa o incompleta, instituto profesional / centro de formación técnica completo o universitaria incompleta. Categoría de referencia: educación universitaria completa o más).

En todos estos casos la hipótesis central es que aquellos con una posición más desfavorable en el mercado laboral (mujeres y las personas con menor educación) tienen más probabilidades de sostener una conciencia de clase trabajadora que aquellos más beneficiados (hombres y personas más educadas). Para la variable "jefe de hogar", la hipótesis es que aquellos definidos como jefes de hogar tienen más posibilidades de tener conciencia de clase trabajadora más fuerte en virtud de sus mayores responsabilidades como jefes de hogar y de su posible contacto con experiencias críticas (desigualdad salarial, desempleo, etc.), las cuales serían menos problemáticas para quienes no son jefes de hogar. De modo similar, a partir del alto nivel de centralismo de Chile y las últimas movilizaciones regionalistas, se plantea la hipótesis de que quienes no viven en la RM tienen más probabilidades de sostener una conciencia de clase trabajadora (o al menos una conciencia más crítica del régimen neoliberal) que quienes sí viven en ella. Finalmente, considerando la debilidad que en las últimas décadas han tenido las movilizaciones abiertamente clasistas, se plantea la hipótesis de que a mayor edad, mayor conciencia de clase trabajadora.

\subsubsection{Variables laborales}

A fin de evaluar el impacto de las condiciones laborales sobre la conciencia de clase, diversas variables fueron incluidas en los modelos de regresión. Estas variables fueron: 1. ingreso promedio mensual: conjunto de variables dummy (1. $\$ 150.000$ o menos, 2. Entre $\$ 150.001$ y $\$ 500.000$, 3. Entre $\$ 500.001$ y $\$ 2.000 .000$. Categoría de referencia: $\$ 2.000 .001$ o más) ${ }^{2}$. 2. Relación contractual: conjunto de variables dummy que representan el tipo de regulación contractual del entrevistado (1. Sin contrato, 2. Contrato temporal. Categoría de referencia: Contrato permanente). 3. Posesión de un segundo empleo: variable dummy que indica si el encuestado posee otro empleo además de su trabajo principal (referencia: no posee segundo empleo). 4. Sector de trabajo: variable dummy que indica si el encuestado trabaja

2 Los límites de estas categorías son aproximados debido a que la medición del ingreso varió ligeramente en ambas encuestas. 
en el sector público o privado (categoría de referencia: sector privado). 5. Sindicalización: variable dummy que indica si el encuestado se encuentra afiliado a algún sindicato (categoría de referencia: no sindicalizado).

La hipótesis general detrás de la inclusión de todas estas variables es que aquellos con las condiciones laborales más desfavorables (bajos salarios, condición contractual precaria) serán más proclives a tener una conciencia de clase trabajadora más fuerte. Siguiendo lo planteado por Wallace y Junisbai (2004: 404), la posesión de un segundo empleo puede ser visto "como una estrategia por medio del cual los trabajadores tratan de asegurar las limitadas oportunidades de empleo en el futuro". Por ello, la hipótesis es que aquellos que cuentan con un segundo empleo tienen más probabilidades de sostener mayores niveles de conciencia de clase trabajadora que quienes no tienen un segundo empleo (que son, probablemente, los que gozan de mejores posiciones en el mercado del trabajo). Finalmente, tomando en cuenta la historia reciente de Chile -especialmente el rol central que jugaron los sindicatos y el empleo público en la generación de espacios de acción colectiva clasista-, se plantea la hipótesis de que quienes se encuentran sindicalizados o trabajan en el sector público tienen mayores niveles de conciencia de clase trabajadora que quienes no están sindicalizados o trabajan en el sector privado.

\subsubsection{Explicaciones ideológicas de la desigualdad}

A fin de evaluar la manera en la que las explicaciones utilizadas por las personas para dar cuenta de fenómenos asociados a la desigualdad social afectan la conciencia de clase, los modelos de regresión incluyeron una última variable definida como Explicaciones del éxito económico. Esta variable fue construida a partir de las respuestas al enunciado "Según su opinión, ¿cuáles son los dos factores más importantes para explicar el éxito económico de las personas?". Aunque las respuestas variaron ligeramente en ambas encuestas, ellas fueron reunidas en dos grandes grupos: 1. Explicaciones meritocráticas/individualistas (por ejemplo, "trabajo duro", "voluntad para hacer dinero sin importar cómo", "ser responsable", etc.) y 2. Explicaciones estructurales ("provenir de una familia con recursos", "tener un buen apellido", etc.).

Ya que los encuestados tuvieron que escoger dos alternativas, ambas alternativas fueron integradas en una misma variable de tres categorías: 1. Explicación meritocrática/ individualista (cuando ambas respuestas del encuestado coincidieron en explicación definida como tal), 2. Explicación estructural (cuando en ambos casos se eligió una alternativa de tipo estructural) y 3. Explicación mixta (cuando la primera respuesta no coincidió con la segunda). Esta variable fue incluida como dummy. La categoría de referencia fue "explicación meritocrática/individualista". Siguiendo las ideas planteadas por la tesis de la "ideología dominante" (Huber y Form, 1973; Kluegel y Smith, 1986), la hipótesis detrás de la inclusión de esta variable es que aquellos que poseen una explicación estructural de la desigualdad y del éxito económico tienen una conciencia de clase trabajadora más fuerte que quienes sostienen explicaciones individualistas de tales fenómenos. 


\section{RESULTADOS}

En la Tabla 1 se observan los estadísticos descriptivos para cada una de las variables dependientes representativas de la conciencia de clase, así como la base de datos de donde fueron obtenidas. Como se puede observar, la identidad de clase y la percepción de conflictos se encuentran menos polarizados que el apoyo a la intervención estatal, en la medida en que la gran mayoría de los encuestados (73\% y 68\%) tiende a poseer niveles intermedios de ambos componentes de la conciencia de clase. Si bien la mayoría de los encuestados también tiene un nivel moderado de apoyo a la intervención estatal (37\%), existe mucha más polarización de actitudes en la medida en que una proporción no menor de los encuestados -casi el 34\%- apoya fuertemente tal tipo de medidas económicas.

TABLA 1

Estadísticos descriptivos de la muestra (variables dependientes)

\begin{tabular}{|l|c|c|c|c|}
\hline VARIABLES DEPENDIENTES & $\begin{array}{c}\text { BAJO } \\
(\%)\end{array}$ & $\begin{array}{c}\text { MODERADO } \\
(\%)\end{array}$ & $\begin{array}{c}\text { FUERTE } \\
(\%)\end{array}$ & $\begin{array}{c}\text { BASE DE DATOS } \\
\text { DE ORIGEN }\end{array}$ \\
\hline $\begin{array}{l}\text { 1. Identidad de clase subordinada } \\
(\mathrm{n}=787)\end{array}$ & 2,92 & 73,06 & 24,02 & Encuesta CIES, 2010 \\
\hline $\begin{array}{l}\text { 2. Percepción de conflictos entre } \\
\text { trabajadores y la administración de la } \\
\text { empresa ( } \mathrm{n}=1.049)\end{array}$ & 11,53 & 67,78 & 20,69 & $\begin{array}{l}\text { Encuesta de Trabajo } \\
\text { y Equidad, 2008 }\end{array}$ \\
\hline $\begin{array}{l}\text { 3. Apoyo a la intervención del Estado en } \\
\text { la economía ( } \mathrm{n}=794)\end{array}$ & 28,97 & 37,28 & 33,75 & Encuesta CIES, 2010 \\
\hline
\end{tabular}

La Tabla 2 muestra los porcentajes y frecuencias de una de las principales variables independientes de este estudio, la posición de clase, para cada una de las bases de datos usadas. Según se observa, la pauta general presentada por ambas encuestas es básicamente la misma: la estructura de clases de la sociedad chilena contemporánea está compuesta en su mayoría por trabajadores manuales no calificados (ellos representan entre el 22\% y 24\%, dependiendo de la encuesta) y miembros de la pequeña burguesía (quienes son entre el $18 \%$ y el $21 \%$ de la población ocupada). Las clases menos numerosas, por el contrario, son los empleados de rutina de nivel alto (5\%) y la clase de servicio alta, cuyos porcentajes varían entre el $5 \%$ y el 9\%. Como se puede observar, la mayor variación entre ambas encuestas se encuentra en los porcentajes que representan a la clase de servicio alta y baja. En el caso de la Encuesta CIES se sobreestimó la clase de servicio alta mientras que en la Encuesta de Trabajo y Equidad se la subestimó (dicha variación explica, en efecto, la diferencia de porcentajes que también se da en la clase de servicio baja). Si bien el algoritmo usado para construir el esquema de clases fue el mismo, es muy probable que las variaciones porcentuales se expliquen por diferencias menores en la medición de la variable definida como "supervisión del trabajo de otros". 
TABLA 2

Estadísticos descriptivos

(variable independiente: clase social)

\begin{tabular}{|c|c|c|c|c|}
\hline \multirow{3}{*}{ VARIABLE INDEPENDIENTE: POSICIÓN DE CLASE } & \multicolumn{4}{|c|}{ BASE DE DATOS DE ORIGEN } \\
\hline & \multicolumn{2}{|c|}{$\begin{array}{c}\text { TRABAJOY } \\
\text { EQUIDAD, } 2008\end{array}$} & \multicolumn{2}{|c|}{ CIES, 2010} \\
\hline & FREC. & $\%$ & FREC. & $\%$ \\
\hline Clase de servicio alta (capitalistas + gerentes de nivel alto) & 109 & 5,38 & 75 & 9,45 \\
\hline Clase de servicio baja & 303 & 14,96 & 82 & 10,33 \\
\hline Empleados no manuales de rutina de nivel alto & 97 & 4,79 & 44 & 5,54 \\
\hline Empleados no manuales de rutina de nivel bajo & 143 & 7,06 & 67 & 8,44 \\
\hline Pequeña burguesía (autoempleados + pequeños empresarios) & 423 & 20,88 & 142 & 17,88 \\
\hline Trabajadores manuales calificados & 268 & 13,23 & 105 & 13,22 \\
\hline Trabajadores manuales no calificados & 439 & 21,67 & 194 & 24,43 \\
\hline Trabajadores agrícolas & 244 & 12,04 & 85 & 10,71 \\
\hline Total & 2.026 & 100 & 794 & 100 \\
\hline
\end{tabular}

La siguiente Tabla muestra los modelos de regresión logística ordinal usados para analizar la relación entre las variables independientes y cada una de las dimensiones de la conciencia de clase. Con relación al primer componente (identidad de clase subordinada), los coeficientes para la clase social muestran que, controlando por todas las otras variables del modelo, quienes no pertenecen a la categoría de referencia -clase de servicio altatienen más probabilidades de sostener una identidad de clase subordinada fuerte, en relación con quienes sí pertenecen a ella. En efecto, a excepción de los miembros de la clase de servicio baja cuya identidad de clase no difiere significativamente de la categoría de referencia, todas las otras clases tienden a sostener una identidad de clase subordinada más fuerte que la clase de servicio. Lo mismo puede ser sostenido para la variable "clase de origen" (en ambos casos los log-odds para la categoría de trabajadores agrícolas son los que más generan diferencias en la identidad de clase). En dicho modelo de regresión se puede observar también que algunas variables demográficas como el lugar de residencia, el estatus de jefe de hogar y el nivel educacional se encuentran relacionadas significativamente con variaciones en la identidad de clase subordinada. A excepción del lugar de residencia, todos los resultados son consistentes con las hipótesis planteadas en un comienzo (jefes de hogar y personas con menor nivel educacional poseen una identidad de clase subordinada 
más fuerte). Contrario a la hipótesis, los residentes de la RM poseen una identidad de clase subordinada más fuerte que quienes no viven en ella. Finalmente, este modelo de regresión muestra que entre todas las variables laborales el ingreso es la única que genera diferencias significativas en la variable dependiente: tal como se planteó hipotéticamente, a menor ingreso mensual mayores los niveles de identidad de clase subordinada.

En relación con la segunda dimensión de la conciencia de clase, percepción de los conflictos entre trabajadores y ejecutivos (administración de la empresa), el modelo de regresión muestra que si bien la posición de clase se relaciona significativamente con variaciones en la percepción de tales conflictos, tal relación no existe para la clase de origen. Controlando por las otras variables del modelo, los miembros de las tres clases "bajas" (trabajadores manuales calificados, trabajadores manuales no calificados y trabajadores agrícolas) tienen más probabilidades que los miembros de la clase de servicio alta de percibir conflictos fuertes entre los trabajadores y la administración de la empresa en la que ellos trabajan. Es interesante notar que el coeficiente para la clase de servicio baja muestra que los miembros de esa clase perciben niveles de conflictos más altos (aunque no tan altos como la clase trabajadora) que los miembros de la clase de servicio alta. Esto puede explicarse por el estatus de supervisión directa que los miembros de la clase de servicio baja poseen en el marco de las relaciones de producción. Tal supervisión puede hacerlos estar en contacto directo con la clase trabajadora -particularmente, como intermediarios entre los conflictos que surgen entre ellos y las posiciones más altas de la empresa-. Así, ellos podrían percibir mayores niveles de conflicto que los miembros de la clase de servicio alta no porque se encuentren más cercanos ideológicamente a la clase trabajadora, sino más bien por ser uno de los actores principales (ubicados en el lado opuesto a los trabajadores) de los conflictos laborales.

En dicho modelo de regresión también se puede observar que las percepciones del conflicto entre trabajadores y empresarios están influenciadas por la edad (contrario a lo planteado en la hipótesis, a menor edad más fuerte la percepción del conflicto entre trabajadores y la administración de la empresa) y por dos variables laborales: la sindicalización y el tipo de contrato. Manteniendo controladas todas las variables incluidas en el modelo, aquellos que se encuentran sindicalizados tienen más probabilidades de percibir niveles de conflicto más fuertes que quienes no lo están. Esto sugiere que a pesar de su debilidad e incluso la orientación proempresa de muchos sindicatos en Chile, la sindicalización sigue siendo una fuente importante de conciencia oposicional de clase. El coeficiente para el tipo de contrato sugiere que la principal distinción contractual que genera variaciones significativas en las percepciones del conflicto entre trabajadores y ejecutivos es aquella entre quienes tienen contrato permanente y quienes tienen contrato temporal, antes que la distinción entre quienes tienen contrato (cualquiera sea él) y quienes no tienen. En efecto, el modelo indica que las percepciones de quienes no tienen contrato son iguales a las de la categoría de referencia (trabajadores con contrato indefinido). Por el contrario, los trabajadores con contrato temporal tienen significativamente más probabilidades de percibir conflictos fuertes entre trabajadores y ejecutivos que los con contrato indefinido. 
Por último, el modelo de regresión para el componente de la conciencia de clase definido como "estatismo económico" (es decir, el nivel de apoyo a la intervención del Estado en la economía expresado en el control estatal de las principales empresas del país) muestra que este no está determinado por la posición de clase de los individuos. Sin embargo, la influencia de los aspectos asociados a la clase se encuentran expresados en la influencia derivada del origen de clase. Controlando por las otras variables del modelo, una persona con origen de clase trabajadora manual calificada tiene más probabilidades de apoyar la intervención del Estado en la economía con relación a una persona con origen en la clase de servicio alta. Esto puede indicar la persistencia temporal de una de las principales divisiones ideológicas presentes en Chile desde, al menos, la segunda mitad del siglo XX. Como es sabido, una de las principales características de la clase trabajadora chilena durante el siglo XX fue su fuerte nexo con partidos políticos de izquierda. Aquellos vínculos, desarrollados fundamentalmente a través de los sindicatos, terminaron siendo la fuerza social determinante de la elección de Salvador Allende en 1970. Durante su gobierno tanto Allende como parte de su coalición política fomentaron una serie de políticas redistributivas orientadas a beneficiar a la clase trabajadora, las cuales incluyeron la expropiación de empresas privadas. Fenómenos históricos y ligados al conflicto de clase como estos pueden explicar el hecho de que, a pesar de la profunda transformación social y política de Chile -la cual incluyó 17 años de dictadura militar-, las personas con un origen de clase trabajadora sigan apoyando políticas económicas estatistas. Algo similar puede ser dicho para el caso de la sindicalización. Controlando por las otras variables del modelo, aquellos que se encuentran sindicalizados son más proclives a apoyar más fuertemente la intervención del Estado en la economía en comparación a quienes no están sindicalizados. Como en el caso de los orígenes de clase, es probable que esta postura de los trabajadores sindicalizados refleje las dinámicas históricas del conflicto de clases presentes en las últimas décadas en Chile.

Junto con estas dos variables, el modelo de regresión indica que el apoyo a la intervención del Estado en la economía está también afectado por variables como el nivel educacional y el tipo de contrato. Manteniendo controladas las otras variables del modelo, aquellos con menores niveles educacionales tienen más probabilidades de apoyar la intervención estatal en la economía en comparación con los de la categoría de referencia (educación universitaria completa o más). De modo similar, aquellos trabajadores que poseen contrato temporal tienen más probabilidades de apoyar la intervención estatal en la economía que aquellos con contrato indefinido. Como en el caso anterior (percepciones del conflicto entre trabajadores y ejecutivos) la principal distinción contractual parece estar basada en las diferencias entre aquellos con contratos permanentes y temporales, antes que en las diferencias entre quienes tienen y no tienen contrato.

En términos generales, los resultados de la Tabla 3 muestran que existen claros determinantes de clase en las tres dimensiones de la conciencia de clase analizadas. Mientras la posición de clase estructura notoriamente los dos niveles más básicos de la conciencia de clase (identidad de clase y conciencia de la oposición de clase), el origen de clase y los fenómenos histórico-biográficos asociados a él estructuran tanto la identidad de clase como los intereses de clase expresados en el apoyo/rechazo de la intervención estatal en la economía. De manera 
TABLA 3

Coeficientes de regresión logística ordinal para cada componente de la conciencia de clase en Chile

\begin{tabular}{|c|c|c|c|c|c|c|}
\hline & \multicolumn{2}{|c|}{$\begin{array}{l}\text { IDENTIDAD } \\
\text { DE CLASE } \\
\text { SUBORDINADA }\end{array}$} & \multicolumn{2}{|c|}{$\begin{array}{l}\text { PERCEPCIÓN DE } \\
\text { CONFLICTOS }\end{array}$} & \multicolumn{2}{|c|}{$\begin{array}{l}\text { ESTATISMO } \\
\text { ECONÓMICO }\end{array}$} \\
\hline & COEF. & E.E. & COEF. & E.E. & COEF. & E.E. \\
\hline \multicolumn{7}{|c|}{ Posición de clase (categoría de referencia: clase de servicio alta) } \\
\hline Clase de servicio baja & 0,564 & 0,466 & $0,580^{*}$ & 0,292 & $-0,153$ & 0,316 \\
\hline $\begin{array}{l}\text { Empleados no manuales de rutina de } \\
\text { nivel alto }\end{array}$ & $1,520^{* *}$ & 0,553 & 0,404 & 0,371 & $-0,347$ & 0,387 \\
\hline $\begin{array}{l}\text { Empleados no manuales de rutina de } \\
\text { nivel bajo }\end{array}$ & $1,006+$ & 0,521 & $0,613+$ & 0,367 & 0,061 & 0,364 \\
\hline Pequeña burguesía & $1,368^{* *}$ & 0,484 & - & - & 0,378 & 0,331 \\
\hline Trabajadores manuales calificados & $0,994^{*}$ & 0,483 & $0,974^{* *}$ & 0,325 & $-0,121$ & 0,332 \\
\hline Trabajadores manuales no calificados & $1,291^{* *}$ & 0,456 & $0,920^{* *}$ & 0,333 & $-0,199$ & 0,312 \\
\hline Trabajadores agrícolas & $1,649^{* *}$ & 0,499 & $0,912^{*}$ & 0,385 & $-0,009$ & 0,362 \\
\hline \multicolumn{7}{|c|}{ Origen de clase (categoría de referencia: clase de servicio alta) } \\
\hline Clase media & $1,575^{* *}$ & 0,456 & 0,056 & 0,434 & 0,473 & 0,292 \\
\hline Trabajador manual calificado & $1,324 * *$ & 0,474 & $-0,081$ & 0,422 & $0,757^{*}$ & 0,309 \\
\hline Trabajador manual no calificado & $1,399 * *$ & 0,467 & 0,206 & 0,439 & 0,309 & 0,303 \\
\hline Trabajadores agrícolas & $1,895^{* * *}$ & 0,486 & 0,069 & 0,442 & 0,529 & 0,327 \\
\hline \multicolumn{7}{|l|}{ Variables demográficas } \\
\hline Mujer & $-0,165$ & 0,202 & 0,091 & 0,172 & $-0,068$ & 0,156 \\
\hline Edad & $0,014+$ & 0,008 & $-0,015^{*}$ & 0,007 & 0,001 & 0,006 \\
\hline Jefe de hogar & $0,468^{*}$ & 0,225 & 0,084 & 0,173 & $0,384^{*}$ & 0,168 \\
\hline Habitante RM & $0,397^{*}$ & 0,199 & $-0,190$ & 0,172 & $-0,109$ & 0,153 \\
\hline Educación básica o menos & $1,096^{*}$ & 0,462 & 0,151 & 0,321 & 0,414 & 0,327 \\
\hline Educación secundaria & $0,717 \dagger$ & 0,415 & 0,030 & 0,264 & $0,478+$ & 0,278 \\
\hline
\end{tabular}




\begin{tabular}{|c|c|c|c|c|c|c|}
\hline & \multicolumn{2}{|c|}{$\begin{array}{l}\text { IDENTIDAD } \\
\text { DE CLASE } \\
\text { SUBORDINADA }\end{array}$} & \multicolumn{2}{|c|}{$\begin{array}{c}\text { PERCEPCIÓN DE } \\
\text { CONFLICTOS }\end{array}$} & \multicolumn{2}{|c|}{$\begin{array}{l}\text { ESTATISMO } \\
\text { ECONÓMICO }\end{array}$} \\
\hline & COEF. & E.E. & COEF. & E.E. & COEF. & E.E. \\
\hline IP/CFT o universitaria incompleta & 0,166 & 0,422 & 0,302 & 0,275 & $0,803^{* *}$ & 0,285 \\
\hline \multicolumn{7}{|l|}{ Variables laborales } \\
\hline Ingreso I ( $\$ 150.000$ o menos) & $1.273^{* * *}$ & 0,361 & 0,150 & 0,379 & 0,271 & 0,284 \\
\hline Ingreso II (\$150.001 - \$500.000) & 0,224 & 0,305 & 0,203 & 0,360 & 0,176 & 0,231 \\
\hline Ingreso III (\$500.001 - \$2.000.000) & $-0,382$ & 0,424 & 0,033 & 0,403 & 0,007 & 0,297 \\
\hline Contrato temporal & 0,118 & 0,231 & $0,435^{*}$ & 0,172 & $0,349 *$ & 0,178 \\
\hline Sin contrato & $-0,189$ & 0,329 & 0,026 & 0,217 & 0,392 & 0,267 \\
\hline Posesión segundo empleo & 0,172 & 0,288 & 0,364 & 0,335 & $-0,037$ & 0,218 \\
\hline Sector público & 0,534 & 0,326 & $-0,169$ & 0,194 & 0,269 & 0,248 \\
\hline Sindicalizado & $-0,340$ & 0,310 & $0,597^{* *}$ & 0,189 & $0,454^{*}$ & 0,229 \\
\hline \multicolumn{7}{|c|}{ Explicación ideológica del éxito económico } \\
\hline Mixta & $-0,189$ & 0,291 & 0,138 & 0,161 & 0,023 & 0,222 \\
\hline Estructural & 0,234 & 0,377 & 0,228 & 0,178 & 0,158 & 0,294 \\
\hline Threshold 1 & \multicolumn{2}{|c|}{0,051} & \multicolumn{2}{|c|}{$-1,370$} & \multicolumn{2}{|c|}{0,560} \\
\hline Threshold 2 & \multicolumn{2}{|c|}{5,750} & \multicolumn{2}{|c|}{2,218} & \multicolumn{2}{|c|}{2,206} \\
\hline Likelihood Ratio $\chi^{2}$ & \multicolumn{2}{|c|}{$162,40^{* * *}$} & \multicolumn{2}{|c|}{$56,57^{* * *}$} & \multicolumn{2}{|c|}{$42,57^{*}$} \\
\hline Pseudo $R^{2}$ & \multicolumn{2}{|c|}{0,154} & \multicolumn{2}{|c|}{0,035} & \multicolumn{2}{|c|}{0,025} \\
\hline $\mathrm{N}$ & \multicolumn{2}{|c|}{782} & \multicolumn{2}{|c|}{959} & \multicolumn{2}{|c|}{789} \\
\hline
\end{tabular}

Nota: Las variables omitidas son "Clase de servicio alta" (para posición de clase y origen de clase), "Hombre" (para género), "No jefe de hogar" (estatus de jefe de hogar), "No habita en RM" (para lugar de residencia), "Educación universitaria completa" (para nivel educacional), \$2.000.001 o más (para ingreso), "Contrato de trabajo permanente" (para tipo de contrato), "Sector privado" (para sector de empleo), "No sindicalizado" (para sindicalización) y "Explicación individualista" (para explicación del éxito económico).

a Las preguntas sobre los conflictos laborales fueron respondidas solo por los trabajadores asalariados. Por eso, aquellos clasificados como "Pequeños burgueses" no están incluidos en el análisis. $+\mathrm{p}<0,10 ;{ }^{*} \mathrm{p}<0,05 ;{ }^{* *} \mathrm{p}<0,01 ;{ }^{* * *} \mathrm{p}<0,001$ (two-tailed). 
interesante, estos determinantes de clase son significativos incluso luego de que la relación es controlada por importantes variables como el género, el ingreso y el nivel educacional.

Los modelos de regresión también muestran que mientras existen variables como el género, el sector de trabajo y las explicaciones ideológicas del éxito económico que no afectan significativamente a las dimensiones de la conciencia de clase acá analizadas, existen otras que sí lo hacen. Por ejemplo, el ser jefe de hogar, vivir en la Región Metropolitana (y no vivir fuera de ella, como se planteó hipotéticamente), tener bajo nivel de educación e ingreso afectan positivamente la emergencia de una identidad de clase subordinada. De modo similar, mientras el ser jefe de hogar, tener contrato de trabajo temporal y estar sindicalizado afecta positivamente la percepción de mayores conflictos entre trabajadores y ejecutivos, la posesión de una conciencia de clase prointervención del Estado en la economía se ve potenciada por el hecho de estar sindicalizado, tener contrato temporal y poseer un nivel educacional técnico profesional o universitario incompleto. Esto último podría ser la expresión del actual movimiento estudiantil compuesto no solo por estudiantes de universidades tradicionales, sino también por una emergente población "crítica" de estudiantes provenientes de Institutos Profesionales y Centros de Formación Técnica. Es probable que ellos hayan sido uno los sectores más desfavorecidos con el endeudamiento asociado al crecimiento de la educación superior privada desde inicios de los años 90. Por eso, no es raro que sean precisamente ellos quienes tengan un interés proestatista más marcado.

\subsection{Entendiendo las variaciones en la conciencia de clase}

Como se ha podido ver, existen dimensiones de la conciencia de clase -por ejemplo, la identidad de clase y la percepción de conflictos- en las que la posición de clase juega un rol estructurador fundamental. Tal importancia de la posición de clase sirve como argumento empírico para validar el enfoque estructural de la conciencia de clase.

Hasta ahora los análisis presentados han estado basados en modelos de regresión logística ordinal cuyos coeficientes (log-odds) no pueden ser directamente interpretables en medidas cuantitativas. A fin de apreciar más claramente cómo la posición de clase produce variaciones en la conciencia de clase es necesario elaborar medidas más claras de dicha relación. Para ello se calcularon las probabilidades estimadas de tener una identidad de clase subordinada "fuerte" y de percibir "altos" niveles conflicto entre trabajadores y ejecutivos (es decir, las categorías más altas de ambas variables), para cada una de las ocho posiciones de clase. La estimación de tales probabilidades se basó en los coeficientes de la variable posición de clase en cada modelo de regresión respectivo, manteniendo todas las otras variables constantes en sus valores modales (para el caso de las variables dummy) o en sus medias (para el caso de la variable de intervalo edad). Los cálculos se ejecutaron a través del comando prvalue para STATA (Long y Freese, 2005). Las probabilidades estimadas se muestran en los gráficos 1 y 2.

Como se observa en los gráficos, la clase de servicio alta es la clase que tiene menos probabilidades de poseer una identidad de clase subordinada "fuerte" y de percibir "altos" niveles de conflicto entre trabajadores y ejecutivos. Por el contrario, las probabilidades más altas para ambas dimensiones de la conciencia de clase se encuentran entre los trabajadores 
agrícolas (para la identidad de clase subordinada) y los trabajadores manuales calificados (para la percepción de los conflictos entre trabajadores y ejecutivos). Al comparar ambas dimensiones se observa que en la sociedad chilena contemporánea la dimensión más polarizada de la conciencia de clase es la referente a la identidad de clase subordinada, al menos en términos de las probabilidades que tienen los individuos de diferentes clases de poseer tal tipo de identidad. En efecto, mientras un miembro de la clase de servicio tiene un $11 \%$ de probabilidades de percibir niveles elevados de conflicto entre trabajadores y ejecutivos, dichas probabilidades son del $24 \%$ para un trabajador manual calificado. Por su parte, mientras un miembro de la clase de servicio alta tiene un $7 \%$ de probabilidad de poseer una identidad de clase subordinada fuerte, tales probabilidades Ilegan a ser casi del $30 \%$ para un trabajador agrícola.
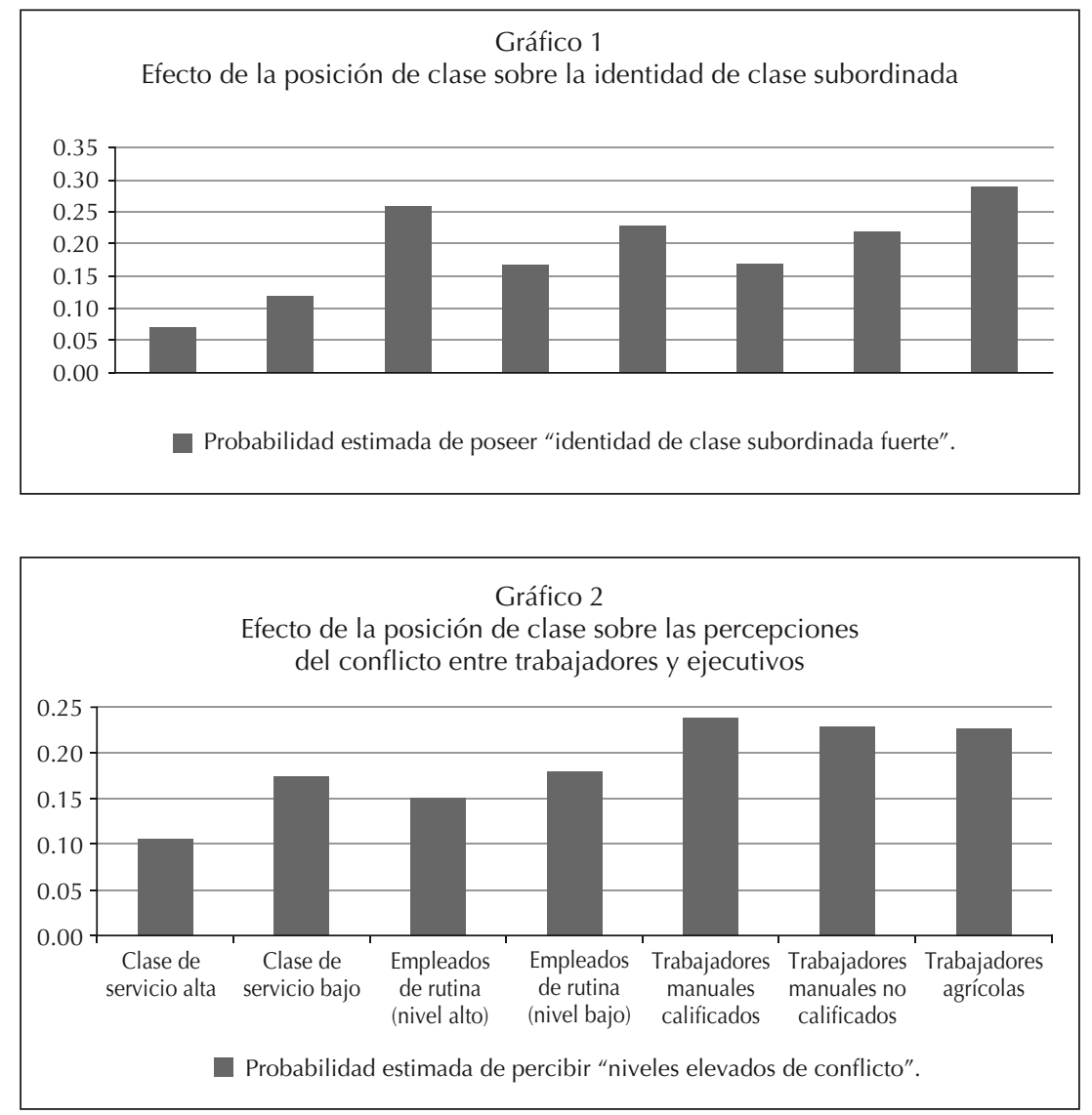

La validación empírica del enfoque estructural de la conciencia de clase no significa, sin embargo, que se deba desestimar la importancia de las experiencias vividas de clase, enfatizada por el enfoque procesual y testeada empíricamente en este trabajo a través de la variable "origen de clase". Los resultados de los modelos de regresión indican, en efecto, que 
tales componentes asociados a las experiencias de clase explican variaciones significativas de la identidad de clase y de los intereses de clase medidos en términos del apoyo a la intervención estatal en la economía. Así, ambos casos entregan soporte empírico a la tesis básica del enfoque procesual de la conciencia de clase. A fin de mostrar más claramente tal argumento, se calcularon las probabilidades estimadas de poseer un nivel "elevado" de estatismo económico (es decir, para la categoría más alta de dicha variable) para cada posición de clase, controlando todas las otras variables del modelo de regresión. Luego de eso, con el objetivo de mostrar la importancia de los aspectos temporales de la clase social, se calculó cómo dichas probabilidades cambiaron después de incluir diferentes orígenes de clase. En otras palabras, se estimó la variación de tales probabilidades en tres casos hipotéticos en donde lo único que cambió fue el origen de clase de los individuos. Estos casos hipotéticos fueron:

1. Origen en la clase de servicio alta

2. Origen en la clase trabajadora manual no calificada

3. Origen en la clase trabajadora manual calificada (recordar que los coeficientes de este tipo de origen de clase fueron los que generaron diferencias significativas en la variable dependiente).

En cada uno de los modelos todas las otras variables se mantuvieron constantes en sus valores modales o promedios. El Gráfico 3 muestra una pauta claramente identificable para todas las posiciones de clase: un cambio en el origen de clase desde uno en la clase de servicio alta (modelo 1) hasta uno en la clase trabajadora manual calificada (modelo 3) se asocia a un incremento en las probabilidades de apoyar la intervención del Estado en la economía. En todos estos casos, el incremento de las probabilidades es alrededor de $15 \%$. Así, por ejemplo, un individuo que se encuentra actualmente en la clase de servicio

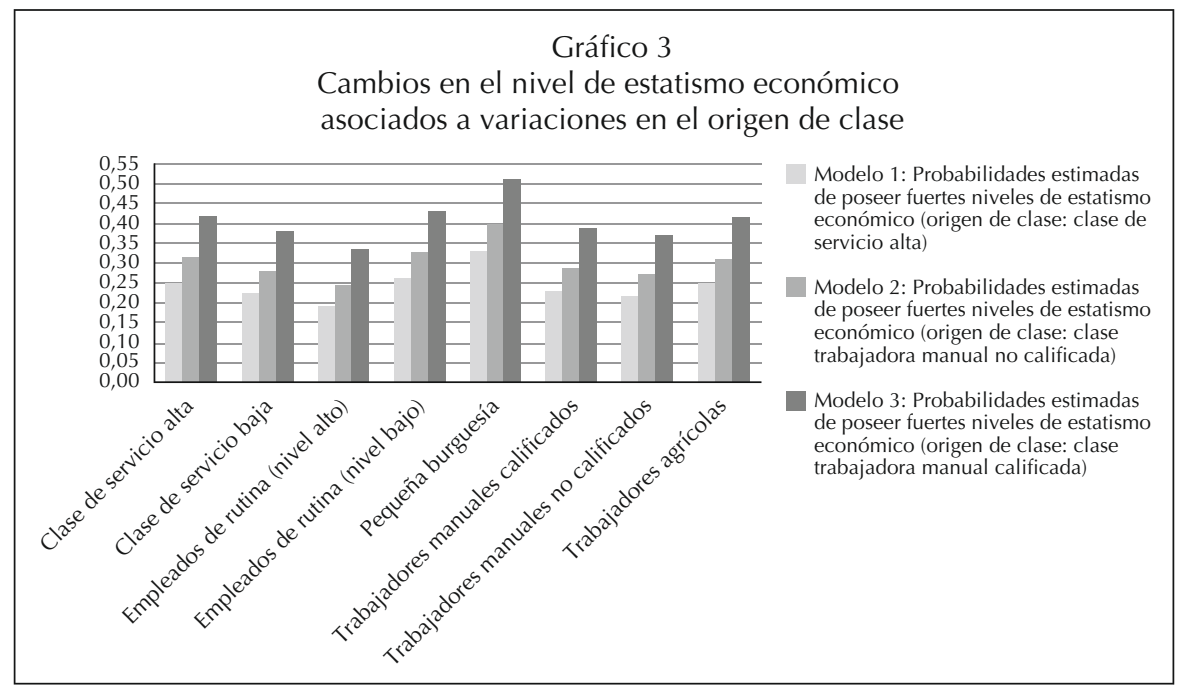


alta y que proviene de una familia de dicha clase social tiene un $25 \%$ de probabilidades de apoyar fuertemente la intervención del Estado en la economía. Si el mismo individuo hubiera nacido en una familia de clase trabajadora manual no calificada tales probabilidades hubieran crecido al 31\%, mientras que si hubiera nacido en un hogar de clase trabajadora calificada las probabilidades crecerían al $42 \%$ (una pauta similar puede verse para todas las otras posiciones de clase). Aunque netamente estadístico, este ejercicio entrega indicios de la manera en que el "efecto" de las experiencias de clase asociadas al origen social afectan significativamente los intereses de clase, como el apoyo a la intervención estatal en la economía.

\section{CONSIDERACIONES FINALES}

Los resultados de esta investigación indican que en una sociedad neoliberal madura como la chilena la clase social es un determinante central de la conciencia sociopolítica de los individuos. De acuerdo con los datos, estos determinantes de clase parecen ser relevantes de dos maneras. En primer lugar, la clase social mostró ser un importante determinante de la identidad de clase y de la conciencia oposicional de los sujetos, a partir de la influencia que la posición que ellos ocupan actualmente en la estructura de clases (posición de clase) tiene sobre tales componentes de la conciencia de clase. Así, tal como ha sido correctamente apuntado por el enfoque estructural, la posición de clase es central al momento de definir la conciencia de clase. Puede que esto no sea sorprendente en una sociedad que, como la chilena, presenta altos niveles de desigualdad. Sin embargo, sí es Ilamativo que la importancia de la clase social se encuentre presente incluso en un régimen económico y político en donde las ideas de clase y de conflicto de clase han sido marginalizadas de los debates políticos nacionales. En efecto, desde inicios del régimen democrático los actores tradicionales de clase trabajadora e incluso de clase media -por ejemplo, sindicatos y asociaciones profesionales- desaparecieron de la escena pública, mientras algunos partidos tradicionales de izquierda (como el Partido Socialista) abandonaron sus discursos de clase. Los resultados de esta investigación muestran que la relevancia estructural de la clase continúa siendo muy fuerte, incluso en escenarios que, como el chileno, han estado definidos por la "ausencia de clases".

La segunda manera en que la clase expresa su impacto sobre la conciencia de clase es, como se señaló, a través de sus aspectos histórico-temporales asociados a las biografías de clase de los individuos. Tal como ha sido explicado por el enfoque procesual, la clase representa un conjunto de mecanismos históricos que configuran las experiencias vividas de los sujetos y, a través de ello, su identidad y sus intereses de clase. Los resultados obtenidos en esta investigación confirman esta idea. En Chile las experiencias de clase son un elemento central en la definición de la identidad de clase subordinada y en las opiniones referentes

a la intervención del Estado en la economía. Estos aspectos histórico-temporales podrían ayudarnos a explicar, nuevamente, por qué la clase sigue siendo todavía un factor central en la configuración de percepciones e intereses sociopolíticos antagónicos, incluso en el marco de un régimen democrático neoliberal caracterizado por su rechazo ideológico a proyectos de clase. 
Sobre la base de estos hallazgos se puede concluir que los elementos tanto estructurales como histórico-procesuales de la clase deben ser considerados en futuros estudios del conflicto de clases en Chile. Esto implica una doble tarea. En primer lugar, se deben mezclar diferentes aproximaciones metodológicas para analizar a los procesos a través de los cuales las distintas clases construyen su conciencia de clase (lo cual supone ser capaces de complementar estudios cuantitativos como este con investigaciones cualitativas que den cuenta del sentido dado por los actores a dicho proceso). En segundo lugar, se debe ampliar el análisis de la conciencia de clase a fin de incluir otras dimensiones de dicho concepto no incluidas en este estudio (por ejemplo, las percepciones sobre los mecanismos que producen desigualdad social, las opiniones sobre la legitimidad del modelo económico o sobre la necesidad de un cambio social).

Esto se presenta como particularmente relevante a la luz del emergente proceso de movilización social experimentado por la sociedad chilena durante los últimos años. Los fundamentos sociales de tal tipo de movilizaciones no están del todo claros todavía, ya que ellas incluyen diversos tipos de demandas y actores sociales -demandas "regionalistas", estudiantiles, y de pobladores, así como nuevas formas de organización social llevadas a cabo por un sindicalismo de nuevo tipo que opera en sectores no tradicionales de la clase trabajadora, como en el sector de servicios y de trabajadores subcontratados-. Sin embargo, a pesar de estas diferencias, todos estos espacios de acción colectivas coinciden de una manera u otra en una crítica básica al modelo de desarrollo chileno, a saber: el régimen neoliberal y la democracia representativa sin real participación política ya no son aceptadas pasivamente como legítimas. Para estos movimientos sociales ni el neoliberalismo ni el régimen democrático cumplieron en Chile lo que alguna vez prometieron: desarrollo económico e inclusión social para todos en un país que, según los defensores de la liberalización económica, se muestra como el más desarrollado de América Latina. Tomando en cuenta los altos niveles de desigualdad social y precariedad económica producidas por el neoliberalismo en Chile, es altamente probable que el principal perjudicado por dicho régimen económico, la clase trabajadora en su sentido amplio, sea uno de los principales soportes sociales de gran parte de estas demandas por un cambio social profundo.

A partir de lo mostrado en esta investigación existen claras fuerzas sociales basadas en dinámicas de clase que están operando detrás de posiciones sociopolíticas antagónicas. Esto sugiere que tanto las causas como las consecuencias de este proceso emergente de movilización social no pueden ser examinadas apropiadamente sin considerar la clase social. Hoy como ayer la clase importa. Por eso, futuras investigaciones deberían analizar cómo en las sociedades neoliberales maduras las clases sociales -en particular las clases subordinadas- pueden superar este escenario social mantenido exitosamente por las clases dominantes hace más de 30 años, que ha sido muy desfavorable para la articulación de sus intereses colectivos. Con ello, podríamos entender cómo las clases operan en la realidad en un contexto político en donde la idea de lucha de clases ha tratado de ser, sin éxito, borrada. 


\section{BIBLIOGRAFÍA}

Angelcos, Nicolás, Pablo A. Pérez y Camilo Sémbler (2006): "Los sectores medios ante la era neoliberal: transformaciones y contradicciones del desarrollo en Chile", Revista de Sociología, 20, pp. 147-165.

Andersen, R. y A. Heath (2002): "Class matters: the persisting effects of contextual social class on individual voting in Britain, 1964-97", European Sociological Review, 18 (2), pp. 125-138.

Ayalon, Hanna, Eliezer Ben-Rafael y Stephen Sharot (1987): "Class consciousness in Israel", International Journal of Comparative Sociology, 28 (3-4), pp. 158-172.

Baltera, Pablo y Juan Pablo Dussert (2010): Liderazgos sindicales emergentes. El caso de los trabajadores subcontratados de la salmonicultura, minería del cobre y forestales, División del TrabajoGobierno de Chile, Santiago.

Barozet, Emmanuelle y Jaime Fierro (2011): "Clase media en Chile 1990-2011. Algunas implicancias sociales y políticas", Konrad Adenauer Stiftung, 4.

Barrett, Patrick (2001): "Labour policy, labour-business relations and the transition to democracy in Chile", Journal of Latin American Studies, 33 (3), pp. 561-597.

Brenner, Johanna (1989): "Work relations and the formation of class consciousness", en Erik Olin Wright: The debate on classes, Verso, New York, pp. 184-190.

Buttel, Frederik H. y William L. Flinn, (1979): "Sources of working class consciousness", Sociological Focus, 12 (1), pp. 37-52.

CEPAL (2006): Panorama social de América Latina 2006, Organización de las Naciones Unidas, Santiago.

Crompton, Rosemary (1993): Class and stratification. An introduction to current debates, Polity Press, Cambridge.

Di Tella, Torcuato, Lucien Brams, Jean-Daniel Reynaud y Alain Touraine (1967): Sindicato y comunidad. Dos tipos de estructura sindical latinoamericana, Editorial del Instituto, Buenos Aires.

Drake, Paul (1996): Labor movements and dictatorships. The Southern Cone in comparative perspective, The John Hopkins University Press, Baltimore.

(2003): "El movimiento obrero en Chile: de la Unidad Popular a la Concertación", Revista de Ciencia Política, XXIII (2), pp. 148-158.

Eichar, Douglas (1989): Occupation and class consciousness in America, Greenwood Press, Westport, Connecticut.

Erikson, Robert y John Goldthorpe (1992): The constant flux. A study of social class mobility in industrial societies, Clarendon Press, Oxford.

Espinoza, Vicente (2006): “La movilidad ocupacional en el Cono Sur. Oportunidades y desigualdad social", Revista de Sociología, 20, pp. 131-146.

Espinoza, Vicente y Emmanuelle Barozet (2009): “¿De qué hablamos cuando decimos 'clase media’? Perspectivas sobre el caso chileno", en Alfredo Joignant y Pedro Güell (eds.): El arte de clasificar a los chilenos. Enfoques sobre los modelos de clasificación en Chile, Ediciones Universidad Diego Portales, Santiago, pp. 103-130.

Evans, Geoffrey (1993): "The decline of class divisions in Britain? Class and ideological preferences in the 1960s and the 1980s", British Journal of Sociology, 44 (3), pp. 449-471. 
(1997): "Political ideology and popular beliefs about class and opportunity: evidence from a survey experiment", British Journal of Sociology, 48 (3), pp. 450-470.

Fantasia, Rick (1988): Cultures of solidarity. Consciousness, action, and contemporary American workers, University of California Press, Berkeley.

Franco, Rolando y Martín Hopenhayn (2010): “Las clases medias en América Latina: Historias cruzadas y miradas diversas", en Rolando Franco, Martín Hopenhayn y Arturo León (eds.): Las clases medias en América Latina, CEPAL y Siglo XXI Editores, México, pp. 7-41.

Frank, Vorlker (2004): "Politics without policy: the failure of social concertation in democratic Chile, 1990-2000", en Peter Winn (ed.): Victims of the Chilean miracle. Workers and neoliberalism in the Pinochet era, 1973-2002, Duke University Press, Durham, pp. 71-124.

Ganzeboom, Harry y Donald Treiman (2003): "Three internationally standardised measures for comparative research on occupational status", en Jürgen H.P. Hoffmeyer-Zlotnik y Christof Wolf (eds.): Advances in cross-national comparison. A European working book for demographic and socioeconomic variables, Kluwer Academic/Plenum Publishers, New York, pp. 159-193.

Giddens, Anthony (1973): The class structure of the advanced societies, Harper \& Row, Barnes \& Noble, New York.

Goldthorpe, John (1982): "On the service class, its formation and future", en A. Giddens y G. Mackenzie (eds.): Social class and the division of labour, Cambridge University Press, Cambridge, pp. 162-185.

Hazelrigg, Lawrence E. (1973): "Aspects of the measurement of class consciousness", en Michael Armer y Allen D. Grimshaw (eds.): Comparative social research. Methodological problems and strategies, John Wiley \& Sons, New York, pp. 219-247.

Hout, Michael, Clem Brooks y Jeff Manza (1995): "The democratic class struggle in the United States, 1948-1992", American Sociological Review, 60 (6), pp. 805-828.

Huber, J. y W. H. Form (1973): Income and ideology, Free Press, New York.

Jones, Andrew W. (2001): "Caring labor and class consciousness: the class dynamics of gendered work", Sociological Forum, 16 (2), pp. 281-299.

Katznelson, Ira (1986): "Working-class formation: constructing cases and comparisons", en Ira Katznelson y Aristide R. Zolberg (eds.): Working-class formation: nineteenth-century patterns in Western Europe and the United States, Princeton University Press, Princeton, pp. 3-41.

Klein, Emilio y Víctor Tokman (2000): "La estratificación social bajo tensión en la era de la globalización", Revista de la CEPAL, 72, pp. 7-30.

Klubock, Thomas M. (2004): "Class, community, and neoliberalism in Chile: coppers workers and the labor movement during the military dictatorship and restoration of democracy", en Peter Winn (ed.): Victims of the Chilean miracle. Workers and neoliberalism in the Pinochet era, 1973-2002, Duke University Press, Durham, pp. 209-260.

Kluegel, James R. y Eliot R. Smith (1986): Beliefs about inequality, Aldine de Gruyter, New York. Lechner, Norbert (1992): “El debate sobre Estado y mercado", Estudios Públicos, 47, pp. 235-247.

Leiva, Fernando (2012): "Flexible workers, gender, and contending strategies for confronting the crisis of labor in Chile", Latin American Perspectives, 39 (4), pp. 102-128.

Leiva, Sandra (2009): "La subcontratación en la minería de Chile: elementos teóricos para el análisis", Polis, 24 (8), pp. 111-131. 
León, Arturo, Ernesto Espíndola y Camilo Sémbler (2010): “Clases medias en América Latina: una visión de sus cambios en las dos últimas décadas", en Rolando Franco, Martín Hopenhayn y Arturo León (eds.): Las clases medias en América Latina, CEPAL y Siglo XXI Editores, México, pp. 43-116.

León, Arturo y Javier Martínez (2007): "La estratificación social chilena hacia fines del siglo XX”, en R. Franco, A. León, and R. Atria (eds.): Estratificación y movilidad social en América Latina. Transformaciones estructurales de un cuarto de siglo, LOM Ediciones, Santiago, pp. 303-338.

Lockwood, David (1975): "Sources of variation in working-class images of society", en Martin Bulmer (ed.): Working-class images of society, Routledge and Kegan Paul, London, pp. 239-250.

(1989 [1958]): The blackcoated worker: a study in class consciousness, Clarendon Press, Oxford.

Long, J. Scott y Jeremy Freese (2005): Regression models for categorical outcomes using Stata (Second edition), Stata Press, College Station, TX.

López, Diego (2009): “La ineficacia de negociar colectivamente en Chile”, en Dirección del TrabajoGobierno de Chile: La negociación colectiva en Chile. La debilidad de un derecho imprescindible, Santiago, pp. 43-71.

Lukács, Georg (1971 [1923]): History and class consciousness, The MIT Press, Cambridge.

Mann, Michael (1973): Consciousness and action among the Western working class, The Macmillan Press, London.

Marshall, Gordon (1983): "Some remarks on the study of working-class consciousness", Politics \& Society, 12 (3), pp. 263-301.

Marshall, Gordon, David Rose, Howard Newby y Carolyn Vogler (1988): Social classes in modern Britain, Routledge, London.

Martínez, Javier y Eugenio Tironi (1985): Las clases sociales en Chile. Cambio y estratificación 19701980, Ediciones Sur, Santiago.

Marx, Karl (1978 [1852]): "The eighteenth brumaire of Louis Bonaparte", en Robert C. Tucker (ed.): The Marx-Engels reader (Second edition), W. W. Norton, New York, pp. 594-617.

Méndez, María L. (2008): "Middle class identities in a neoliberal age: Tensions between contested authenticities", The Sociological Review, 50 (2), pp. 220-237

(2010): "Las clases medias en Chile: transformaciones, sentido de pertenencia y tensiones entre distintos proyectos de movilidad", en Rolando Franco, Martín Hopenhayn y Arturo León (eds.): Las clases medias en América Latina, CEPAL y Siglo XXI Editores, México, pp. 230-288.

Méndez, María L. y M. Gayo (2007): "El perfil de un debate: movilidad y meritocracia. Contribución al estudio de las sociedades latinoamericanas", en R. Franco, A. León, and R. Atria (eds.): Estratificación y movilidad social en América Latina. Transformaciones estructurales de un cuarto de siglo, LOM Ediciones, Santiago, pp. 121-157.

Offe, Claus y Helmut Wiesenthal (1980): "Two logics of collective action: theoretical notes on social class and organizational form", Political Power and Social Theory, 1, pp. 67-115.

Silva, Eduardo (1996): The State and Capital in Chile. Business élites, technocrats, and market economics, Westview Press, Boulder.

Svallfors, Stefan (2006): The moral economy of class. Class and attitudes in comparative perspectives, Stanford University Press, Stanford. 
Thompson, Edward P. (1966): The making of the English working class, Vintage Books, New York.

Torche, Florencia (2006): "Una clasificación de clases para la sociedad chilena", Revista de Sociología, 20, pp. 15-44.

Vallas, Steven P. (1987): "White-collar proletarians? The structure of clerical work and level of class consciousness", The Sociological Quarterly, 28 (4), pp. 523-540.

Vanneman, Reeve y L. Weber Cannon (1987): The American perception of class, Temple University Press, Philadelphia.

Wallace, Michael y Azamat Junisbai (2004): "Finding class consciousness in the New Economy", Research in Social Stratification and Mobility, 20, pp. 385-421.

Weller, Jürgen (2004): "El empleo terciario en América Latina: entre la modernidad y la sobrevivencia", Revista de la CEPAL, 84, pp. 159-176.

Western, Mark (1999): "Who thinks what about capitalism? Class consciousness and attitudes to economic institutions", Journal of Sociology, 35 (3), pp. 351-370.

Winn, Peter (ed.) (2004): Victims of the Chilean miracle. Workers and neoliberalism in the Pinochet era, 1973-2002, Duke University Press, Durham.

Wormald, Guillermo y Florencia Torche (2004): Estratificación y movilidad social en Chile: entre la adscripción y el logro, CEPAL-Organización de las Naciones Unidas, Santiago.

Wright, Erik O. (1985): Classes, Verso, London.

(1997): Class counts: comparative studies in class analysis, Cambridge University Press, Cambridge.

Zingraff, Rhonda y Michael D. Shulman (1984): "Social bases of class consciousness: a study of southern textile workers with a comparison by race", Social Forces, 63 (1), pp. 98-116.

\section{APÉNDICE METODOLÓGICO: DESCRIPCIÓN DE LOS ÍNDICES}

Identidad de clase subordinada: La base de esta variable es el "Índice de identidad de clase subordinada". El índice representa la suma simple de las variables "Autoposicionamiento de

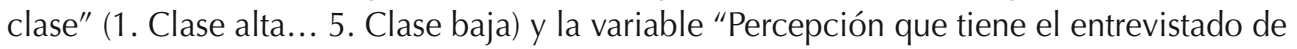
su situación económica personal" (1. Muy buena... 5. Muy mala). Ambas variables fueron sumadas para crear un índice de 2 a 10 puntos (a mayor el valor del índice mayor la identidad de clase subordinada.) Alfa de Cronbach $=0,66$. El índice fue finalmente recodificado en una variable ordinal de tres categorías (Identidad de clase subordinada baja o ausente $=2$ a 4 puntos; Identidad de clase subordinada moderada = 5 a 7 puntos; Identidad de clase subordinada fuerte $=8$ a 10 puntos).

Percepción del conflicto entre trabajadores y la administración de la empresa: Esta variable proviene del "Índice de percepción de conflictos laborales entre trabajadores y la administración de la empresa", que fue construido a partir de las siguientes variables: a) Evaluación del encuestado de su relación con su supervisor directo, b) Evaluación de su relación con otros jefes de la empresa, c) Evaluación de la relación que existe entre los trabajadores y administración de la empresa, y d) Confianza que tiene el entrevistado en las promesas hechas por la administración de la empresa a los trabajadores. Todas esas variables 
fueron sumadas para crear un índice de 4 a 12 puntos (a mayor puntaje percepciones de conflicto más altas). Alfa de Cronbach $=0,74$. Finalmente este índice fue recodificado y transformado en una medida ordinal (Baja percepción de conflictos = 4 a 6 puntos; Percepción moderada = 7 a 9 puntos; Percepción elevada de conflictos $=10$ a 12 puntos). 